\title{
Applicability, potential and limitations of staff-centred energy conservation initiatives in English hospitals
}

Paula Morgenstern, UCL Energy Institute, University College London, London, UK ${ }^{1}$ Rokia Raslan, UCL Institute of Environmental Design and Engineering, UCL, London, UK Gesche Huebner, UCL Energy Institute, University College London, London, UK

\begin{abstract}
Increasing energy costs and climate change legislation have prompted efforts to reduce energy consumption in UK hospitals. In addition to technological conservation strategies focussing on buildings and building services, staff-centred initiatives such as energy awareness campaigns are increasingly being considered by National Health Service (NHS) Trusts due to their potential cost-effectiveness. However, hospitals are complex buildings with unique energy requirements and it is unclear to what extent these requirements are influenced by clinical staff. This paper combines a review of staff-centred energy conservation initiatives in organisations in general and in hospitals in particular with the results of a survey-based study among NHS energy managers $(\mathrm{N}=70)$. The study findings highlight that staff-centred energy conservation initiatives are currently of interest to a majority of NHS trusts in England and may become an increasingly important part of carbon reduction strategies in hospitals in the future. Policy assumptions regarding their savings potential, however, appear to be undifferentiated and it seems advisable to relate behavioural efforts more closely to the physical context of the respective hospital building and its service infrastructure as well as the healthcare processes relevant to different departments.
\end{abstract}

\section{KEYWORDS}

hospitals; energy managers, energy behaviours; NHS; organisational energy use; energy awareness

1 Corresponding author: paula.morgenstern.11@ucl.ac.uk, 14 UPPER WobURn PLACE, LONDON WC1H 0NN, +44(0)20 31085927 


\section{Introduction}

In response to concerns about climate change and in line with legislation in other developed countries, the UK Climate Change Act (2008) mandates an $80 \%$ reduction of greenhouse gas emissions by 2050 compared to the 1990 baseline. To meet this target, all sectors will need to implement reductions and buildings are expected to approach zero carbon footprints by 2050 (DECC 2011). The energy used for heating and powering non-domestic buildings is responsible for $12 \%$ of all UK greenhouse gas emissions (DECC 2011). Within the nondomestic building sector, hospitals are considered to be big energy users with unique requirements (Ziebik and Hoinka 2013): They are continuously occupied by a large number of people, many of whom are vulnerable. Consequently, the thermal environment needs to be controlled carefully; medical requirements also necessitate a strict control of indoor air parameters (especially in operating theatres and treatment rooms) and special medical equipment as well as equipment sterilisation and catering add to the electricity consumption through lighting, air-conditioning and appliances common in non-domestic buildings (Carbon Trust 2010).

In the UK, hospitals are operated by the tax-funded National Health Service (NHS). The NHS is Europe's largest employer (NHS Jobs 2014) and is responsible for the management of approximately $1 \%$ of all UK non-domestic premises (DoH 2006a). The NHS has committed to reducing its total carbon emissions by $10 \%$ by 2015 (based on 2007 baseline data) and in the long term by $80 \%$ up to 2050 (NHS SDU 2013). Energy used in buildings accounts for $17 \%$ of the NHS's total emissions, prompting reduction attempts in this area. In addition, rising energy prices have put pressure on the NHS, whose annual energy expenditure now exceeds $£ 630$ million (ibid). Growth in technology and increased service delivery have also contributed to this tripling in energy costs from £232 million in 2000 within little more than a decade.

In the current economic climate of constraint spending, however, energy projects remain low priority compared to the health service's prime objective of delivering excellent patient care (NHS England 2013). This core health service objective is constantly faced with three challenges: Firstly, a steadily increasing number of patients through demographic change and improved life expectancies (Emmerson et al. 2000). Secondly, higher patient expectations with regard to not only the medical but also the overall qualities of a hospital stay (The King's Fund 2012). And thirdly, the safety of patients and staff and avoiding fatalities will always be central to hospital operation (NHS England 2013). All energy reduction strategies need to operate in this 'trilemma' between carbon, costs and care.

To help healthcare organisations manage the energy use of their buildings, the UK Department of Health publishes the guidance document 'EnCO2de' (latest version as of 2006). In addition, many other non-government bodies offer advice for hospital energy managers, in the UK notably through the Carbon Trust's Carbon Management Programme and previously the Building Research Energy Conservation Support Unit. A range of both historic and current Carbon Management Plans of individual trusts are also available as exemplars, if not as best-practice examples. In other countries such as Germany (Tippköter and Schüwer 2003) or Austria (Benke et al. 2009) comparable although less official guidance documents exist.

Academic research regarding the energy use of existing hospital buildings is sparse, even The final publication is available in "Energy Efficiency" at Springer via http://dx.doi.org/10.1007/s12053-015-9346-2 
within the comparatively under-researched field of non-domestic buildings. While operational and facilities management in hospitals has been studied extensively in order to reduce operational costs (Diez and Lennerts 2010; Jones 2001; McGuire 1987) few have researched energy efficiency in hospitals as such. In contrast, past studies have often focussed on the monitoring of indoor temperatures and air quality issues in certain hospital building types (e.g. Lomas et al. 2012; Short et al. 2012) or parts such as operating rooms (Balaras et al. 2007) and their crucial role for patient well-being and staff performance.

Hospital energy demand reduction strategies have traditionally focussed on technical options to improve buildings and building services through retrofit measures such as insulation, energy efficient lighting, improved heating or lighting controls and higher chiller efficiencies as well as through better energy management (NHS SDU 2010). However, it is increasingly recognized that energy savings in non-domestic buildings may potentially also be achieved through changes in user behaviour (Banks et al. 2013; Jeffries and Rowlands-Rees 2013). The NHS has expressed an interest in this option in the short-term as it is thought that it could be more cost-effective than many technological conservation options (Pencheon et al. 2009). For example, the NHS Sustainable Development Unit assumes a pay-back time for energy awareness campaigns 'that target areas of energy wastage (e.g. encourage switch off lighting and equipment when not in use)' of 0.3 years in large acute trusts and 0.5 years in small or medium acute trusts while delivering energy savings of $3 \%$ (NHS SDU 2010, Tables A1 and A2).

Despite the assumptions of the NHS on the potential of what is commonly referred to as 'people' interventions, little is known about their applicability, potential and limitations across the NHS Estate. A thorough review of relevant literature revealed no academic publications on the topic and many open questions remain in the practical literature. This study aims to shed some light on the issues through a review of the literature on staff-centred energy conservation initiatives in organisations in general and in hospitals in particular. In order to capture unpublished activities in the health sector and create a comprehensive, up-to-date picture, the results of a survey study among energy/ estate managers of NHS Trusts that operate General Acute Hospitals in England will also be presented. In their role as keydecision makers on investment in energy efficiency, their views on potential and limitations of staff-centred initiatives will crucially determine the uptake of such initiatives in the future. 


\section{State of the art: staff-centred energy conservation initiatives}

The following section reviews the literature to identify principles of and evidence for effects of staff-centred energy conservation initiatives in organisations. In the first instance, the term may be understood to comprise any initiative, campaign or programme targeting building users, i.e. the core staff of the organisation occupying the building. Their jobs depend on the organisational focus and will in most cases have nothing to do with energy issues per se. Apart from these permanent building users, many non-domestic buildings are temporarily also occupied by other occupant groups such as hospital visitors who may or may not be coaddressed by initiatives. The focus of any such initiative can be a specific or a range of energy behaviours; from switching off lights afterhours or turning off unused equipment to altering temperature set points during or outside of used hours.

\section{General principles and potential in organisations}

The influence of occupants on building energy consumption was first highlighted in the domestic context (Socolow 1978) and is there now widely acknowledged (Abrahamse et al. 2005). In contrast, there is less research on the impact of occupants on energy use in nondomestic buildings. Increasingly, post-occupancy evaluations have helped understanding how well occupant needs are met in commercial buildings (e.g. Baird 2010) and implications for sustainable building management have been identified (Bordass et al. 2001). However, relatively few studies in the academic literature explicitly investigate staff energy behaviours in organisations. Social and environmental psychology literature reports intervention studies targeting employee energy use using various different approaches such as the provision of information, goal setting and giving feedback or rewards. Abrahamse and Steg (2013) published a meta-analysis of social influence approaches in resource conservation which provides a comprehensive overview of different intervention types. Most of the 29 studies included in their analysis, however, focus on recycling or refer to social situations in neighbourhoods and communities as opposed to in the workplace.

Studies investigating staff-centred conservation initiatives in organisations suggest that measured energy savings can vary between 1 and $12 \%$ for heat and 1.5 to $8 \%$ for electricity while simulations more consistently claim a potential of up to $20 \%$ of total energy use (see Table 1). The table indicates that the interest has so far primarily been in university and office buildings, with a more pronounced interest in electricity compared to heating use.

Table 1: Overview of academic literature on energy behaviour change initiatives in organisations

\begin{tabular}{|l|l|l|l|}
\hline Author(s) & Intervention type $^{2}$ & $\begin{array}{l}\text { Building } \\
\text { typology }\end{array}$ & Effect size \\
\hline Addressing heating and electricity & \multicolumn{3}{|l|}{} \\
\hline Matthies et al 2011 & $\begin{array}{l}\text { Prompts } \\
\text { Commitment }\end{array}$ & University & $\begin{array}{l}\text { Electricity: 8\% } \\
\text { Heating: } 1 \%\end{array}$ \\
\hline Schahn 2007 & $\begin{array}{l}\text { Prompts } \\
\text { Rewards }\end{array}$ & University & $\begin{array}{l}\text { Electricity: 6,5\% } \\
\text { Heating: } 12,4 \%\end{array}$ \\
\hline
\end{tabular}

2 Conceptualized after Osbaldiston \& Schott (2012): Type of treatment employed in a study to encourage behavioural changes

The final publication is available in "Energy Efficiency" at Springer via http://dx.doi.org/10.1007/s12053-015-9346-2 


\begin{tabular}{|l|l|l|l|}
\hline Siero et al 1996 & $\begin{array}{l}\text { Goal setting } \\
\text { Feedback }\end{array}$ & $\begin{array}{l}\text { Metallurgic } \\
\text { company }\end{array}$ & $\sim 6-7 \%$ \\
\hline Addressing heating only & University & $6 \%$ \\
\hline Staats et al 2000 & $\begin{array}{l}\text { Instructions } \\
\text { Feedback }\end{array}$ & $\begin{array}{l}\text { University } \\
\text { (Office) }\end{array}$ & $\begin{array}{l}4-7 \%(\mathrm{vs} \mathrm{4} \% \\
\text { in control) }\end{array}$ \\
\hline Addressing electricity only & University & $6 \%$ \\
\hline $\begin{array}{l}\text { Carrico \& Riemer } \\
2011\end{array}$ & $\begin{array}{l}\text { Feedback } \\
\text { Social modelling }\end{array}$ & University & $<1.5 \%$ \\
\hline $\begin{array}{l}\text { McClelland \& Cook } \\
1980\end{array}$ & Information & Office & $5.4 \%$ \\
\hline Murtagh et al. 2013 & Feedback & Office & $20 \%$ \\
\hline $\begin{array}{l}\text { Nye \& Hargreave } \\
2010\end{array}$ & Social modelling & University & $20 \%$ \\
\hline Simulation addressing heating and electricity \\
\hline Junilla et al 2007 & & Office & $21 \%$ \\
\hline $\begin{array}{l}\text { Kattenstein et al. } \\
2002\end{array}$ & \\
\hline $\begin{array}{l}\text { Azar \& Menassa } \\
2014\end{array}$ & &
\end{tabular}

Generally, employee energy behaviours were shown to be influenced by three main groups of variables (for example Lo et al. 2012; Littleford 2013, Tudor et al. 2008): contextual factors such as the nature of the setting and physical control over environment or equipment; individual level factors such as knowledge, value orientation or self-efficacy; and organisational level factors such as social norms and organisational culture. All of these factors may present levers to encourage energy efficient behaviours in the workplace.

While some intervention types might be comparable between homes and organisations, mechanisms and intervention pathways cannot be translated directly from the domestic into the work area. At home, an individual usually has control over all aspects of energy consumption and is responsible for paying the associated costs. There is, hence, both a direct financial incentive for saving energy and also regular, if delayed, feedback on the amount of energy consumed via the utility bills. In the workplace, both the feedback and the financial incentive are generally missing. Having to make 'sacrifices' by changing one's behaviour to profit the organisation through reduced energy bills could in this context impact negatively on conservation motivation (Cox et al. 2012). Also, equipment in organisations is often shared by many and an individual might be less likely to take action or feel less of a responsibility for doing so (Littleford 2013). On the other hand, behaviours at the workplace are generally rather observable and social norms presumably highly salient (Abrahamse and Steg 2013) which could benefit the transition towards energy efficient behaviours compared to a home environment.

\section{Staff-centred energy conservation initiatives in English hospitals}

A review of the academic literature has revealed a lack of research studies that focus on 
staff-centred energy conservation initiatives in hospitals. However, a handful of case studies in the grey literature have reported on energy awareness campaigns or comparable behavioural initiatives in hospitals. While some report on cost or fuel savings achieved as detailed below, the quoted estimates will need to be interpreted with some caution as methods for their estimation are often unclear and results may be influenced by stakeholder interests.

In England, behavioural energy efficiency in hospitals has been discussed at least two times: in the late 1980s and then again now following a period of reduced interest in behavioural energy efficiency during the 1990s/early 2000s. During the first period, the (then) Department of the Environment published a guide for energy and estate managers on good housekeeping in the NHS (BRECSU 1992) based on experiences acquired in different health authorities during the 1980s. More recently, the NHS Carbon Management Plan was piloted in 2007 in partnership with the Carbon Trust in 30 hospitals throughout England and Wales, with most pilots including some behavioural elements (Carbon Trust 2008). In 2013, a survey among 448 organisations, of which about $8 \%$ were NHS Trusts, found that 'non-technological (and presumably low cost) behaviour change initiatives came in third' among technologies that have been commissioned in the last 12 months, only outperformed by improvements to lighting efficiency and controls (Jeffries and Rowlands-Rees 2013:7).'

An early example of a staff-centred conservation initiative is the good housekeeping programme of the Somerset Health Authority from 1987 (BRECSU 1992), where a combination of technological measures and staff engagement achieved $25 \%$ savings on fuel bills across the estate within three years. Little detailed energy data was available and the sole effect of the staff-centred initiatives could not be separated from technical improvements, but the report attributes roughly a fifth of the savings (5\% of the fuel bill) to the housekeeping measures. Staff were appointed "energy monitors" to watch the day-to-day use of equipment and identify opportunities for savings, while they and their departmental managers received training on energy issues and appreciation sessions. The campaign also recognised the importance of senior management commitment and monthly review meetings with highranking managers were organised.

An interesting approach to motivating staff is reported from the Pinderfields Hospital Trust (BRECSU 1995): Apart from a poster campaign throughout their hospitals and energy handbooks for staff to take home, the trust also implemented departmental accountability in six pilot areas; pre-allocating energy budgets to departments and measuring actual energy use. The project documentation, however, does not indicate whether departments could use money for other purposes if they achieved savings and also how well this intervention performed generally.

More recently, the interest of hospital energy managers in staff-centred energy conservation initiatives has been re-sparked by Carbon Trust claims (2010) that reductions in total energy costs of up to $10 \%$ could be possible from good housekeeping at no or very low cost. The same potential was previously published in the aforementioned 1992 NHS guide, while other official publications for example by the NHS Estates (Brayford 2004) or the NHS Sustainable Development Unit (SDU) (Pencheon et al. 2009) had meanwhile stressed the significance of staff education and participation, but not presented tangible energy saving potentials. For their Marginal Abatement Cost decision support tool the SDU (2010) assumes more conservative energy awareness campaign effect sizes of $3 \%$ reductions for electricity and 
heating respectively.

The NHS SDU also publishes practical advice on and best-practise examples of staff engagement on their website (NHS SDU 2014). One such example was 'Operation TLC' at Barts Health NHS Trust. This award-winning multi-partner behaviour change programme used an Energy Champion approach to promote three low impact, but high frequency energy behaviours (turning off unused equipment, switching of lights and closing doors). The campaign team states that cost-savings of $£ 105,000$ have been achieved alongside with improvement in patient experience through fewer sleep disruptions and less privacy intrusions (Barts Health 2013).

Despite potentially cost-effective reductions from staff-centred energy conservation initiatives in hospitals, many open questions remain. First and foremost, relevance and current uptake of such measures across the NHS Estate are unclear. Also, little research has been done on energy behaviours in hospitals in particular; solely Jensen and Petersen (2011) have looked at reducing the stand-by energy use of medical equipment. More generally, there is a lack of work conceptually linking targeted energy behaviours to the respective building and its interfaces with the occupants, both for hospitals and for other non-domestic buildings. In a recent report for the Department of Energy and Climate Change, Banks and colleagues (2012:48) call this 'end use perspective' and likewise demand more research taking this view. They also point towards unresolved issues regarding the persistence of behaviour change which may reduce the confidence of energy managers in the sustained effect of such initiatives in all non-domestic buildings, including hospitals.

Finally, the UK health context poses some particular challenges for pro-environmental behaviours as Tudor (2008) has pointed out based on his study of waste management in the NHS Cornwall. This is due to the centralised and hierarchical structures of the NHS with high levels of central focus and control. Tudor found that managers regularly prioritised health care related targets while all other issues became secondary. Also, in times of austerity the management shows a certain reluctance to spend money on non-core activities; resulting in low motivation among all staff towards them. More generally, it has also been mentioned that health care professionals are traditionally a group difficult to enthuse for sustainability as they might feel they are already 'doing good' through their profession (Gray 2011).

This review suggests that energy and cost savings through staff-centred conservation initiatives might also be achievable in health care organisations while some challenges remain: Reported reduction estimates are (although associated with some uncertainty) in line with effect sizes reported in the academic literature for offices and university buildings. Challenges, however, are often particular to the hospital context and would benefit from further investigation focussing on energy behaviours and cultural elements relevant in health care. At the same time, it remains unclear whether NHS Trusts are interested in exploring the topic further to meet these challenges or whether a more conservative facilities management style favouring technological options prevails. Further research could hence help to clarify the role of staff-centred initiatives within organisational carbon management strategies taking into account both their potential cost-effectiveness and non-energy effects. 


\section{A survey based study of staff-centred energy conservation initiatives in English hospitals}

As laid out in the review of the state of the art, information on energy behaviour change programmes in hospitals are sparse and often from disperse sources within the grey literature. A survey among hospital energy managers was consequently considered necessary to collect up-to-date information of consistently high quality on the topic.

Energy managers (sometimes also referred to as facilities, carbon reduction or environmental managers) are key stakeholders in defining carbon reduction strategies of organisations and often control spending on energy efficiency projects (Aune et al. 2008). It can hence be expected that they are informed about any staff-centred conservation initiatives going on across their estates. In many cases, they will themselves have been involved in commissioning or implementing such measures while also being aware of bottom-up initiatives put in place by clinical or other staff. Eliciting such knowledge from them through a survey was hence considered a valuable strategy to meet the following objectives:

- To get a better understanding of the relevance of staff-centred energy conservation initiatives for hospitals in England;

- To collect evidence on their potential effect size; and

- To identify challenges for their implementation and evaluation in the hospital context.

In particular, the first objective made it necessary to collect information from a sufficiently large number of hospitals in order to gauge interest at a stock level. A survey study was hence deemed the appropriate method as opposed to interviews and focus groups in order to achieve a large enough sample size. Surveys may also serve to inform the development of more in-depth interview guides (Creswell \& Plano Clark 2011), which could be key in further expanding on the challenges identified through the third objective of this study.

In determining the boundaries of this study, only England was considered at this initial stage due to the structural differences between the healthcare systems in different parts of the UK. Also, it is focussed on General Acute Hospitals which, operated largely by Large Acute (33\%) or Teaching (19\%) trusts, occupy by far the largest floor area within the English NHS Estate (60\% according to the then latest available Estates Return Information Collection (ERIC) from 2011/2012). The average occupied floor area of a General Acute Hospital is roughly $52000 \mathrm{~m}^{2}$, while there is huge variation (Smallest hospital: $759 \mathrm{~m}^{2}$, Largest hospital: $\left.245000 \mathrm{~m}^{2}\right)$. Estate ages also vary widely, the average hospitals being dominated by buildings constructed between 1985 and 1994 (21.6\%), followed by buildings from the years 1995 to $2004(18.7 \%)$.

\section{Survey design}

The survey was designed according to Dillman's principles of tailored survey design to minimise total survey error (Dillman et al. 2008). In the UK, all hospitals are organised within NHS trusts which centrally resume some management functions. In line with the NHS carbon reduction commitments, trusts are advised to appoint energy, environmental or carbon managers within their facilities departments responsible for sustainability and energy issues. 
For the purpose of this paper, they will from now on be referred as energy managers for simplicity. Energy managers mostly work desk-based and are accustomed to the use of computers and the internet, so a web-based survey mode was chosen to reduce coverage error. The survey was implemented using the online hosting platform 'Opinio'.

ERIC 2011/2012 shows that 149 NHS Trusts in England operate at least one General Acute Hospital. The energy managers of these trusts consequently constituted the target population for this survey. To identify the specific survey respondent within each trust four strategies were applied:

1. Trust websites were searched for energy manager contact details;

2. The Carbon Trust Public Sector forum and other web-fora frequented by the target population were checked for contact details;

3. A snowball request for further details was handed out to existing contacts; and if all of the first three contact strategies were unsuccessful then

4. A Freedom of Information (FOI) request enquiring for the energy manager's contact details was sent to the trust in question.

Out of the 149 NHS Trusts, 17 had to be excluded from the study due to a number of reasons (e.g. trusts no longer in existence as in ERIC 2011/2012 due to mergers, hospitals misclassified as General Acute Hospitals in ERIC or energy management contracted out resulting in unclear responsibilities). The total sample hence consisted of 132 trust energy managers.

To reduce non-response error, a varied contact strategy with multiple points of contact was applied. All contacts were personalised based on the established contact details to increase the visibility of the survey and distinguish it from other, more generic surveys which NHS staff receive frequently. It is known that e-mails are often read first thing in the morning (Dillman et al. 2008) so all e-mail contacts were made before 8am hoping to thereby increase survey response. The web-survey itself was accessible via an introductory homepage detailing the study purpose and its relevance to the NHS. The credentials of the research institution as well information on data protection were also displayed to provide assurance to survey respondents. For the same reason, survey response was anonymous and questions for trust characteristics such as size or age which could easily allow for the identification of the trust based on publically available data were omitted. Additionally, the NHS Sustainable Development Unit endorsed the survey in their monthly newsletter and published additional information about it on their website.

In formulating the survey questions and implementing them in the online hosting platform, key recommendations for example by Dillman et al. (2008) were considered in order to minimise measurement error. The question set was developed based on themes emerging from the review as presented and on the experience of the first author in assisting with the recent implementation of an energy behaviour change programme in a large acute hospital. Finally, the input of other experts in two focus groups was taken into account. A complete list of questions can be found in the appendix of this publication. The survey implementation in 'Opinio' and the skip-logic for routing respondents exclusively towards questions relevant to them (shown in Figure 1) were repeatedly tested with non-experts. Also, the completed survey was pilot-tested with three members of the target population and their feedback on framing and phrasing of the questions was incorporated. During this pilot-testing, interviewer input was kept to a minimum to avoid any bias in the response of those individuals when taking the finalized survey.

The final publication is available in "Energy Efficiency" at Springer via http://dx.doi.org/10.1007/s12053-015-9346-2 
Fig. 1 Overview of survey questions and response pathways with diamonds representing major routing points

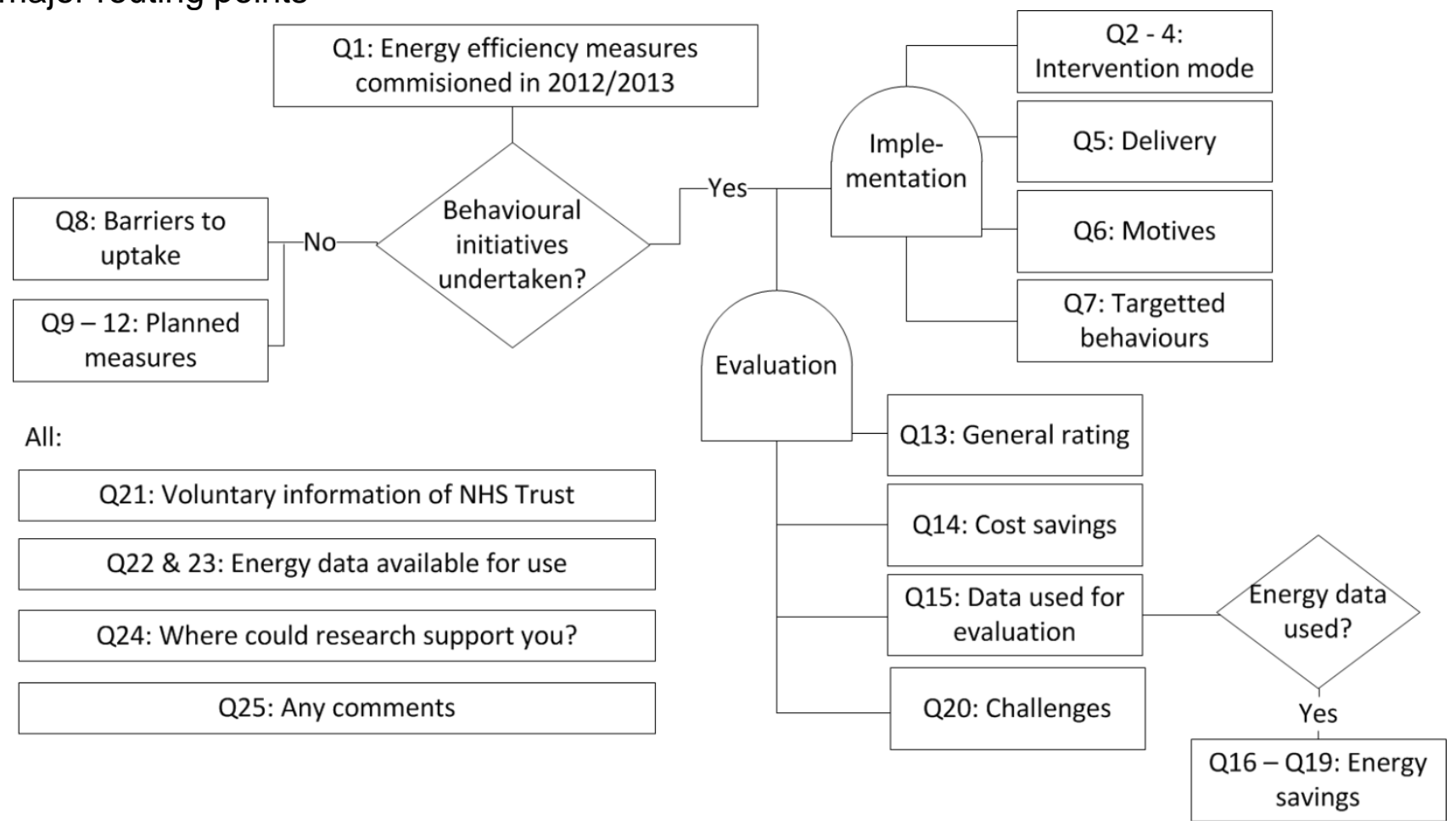

\section{Survey response rates and limitations}

A $47 \%$ response rate to the web-survey was achieved with 62 fully completed surveys from 132 valid respondents; which compares favourably to rates of around $35 \%$ generally expected in similar web-surveys (Fan and Yan 2010; Schonlau et al. 2002). Eight surveys were completed partially; their responses were included into the analysis whenever the answer to a specific question was complete (regardless whether other questions had not been answered.) There are some limitations to the generalizability of the survey results:

- The target population was restricted to England. While fundamental challenges to the implementation and evaluation of staff-centred energy conservation initiatives will be comparable in other (national) health service organisations, their actual uptake and the available energy data might differ due to funding priorities.

- The position of an energy manager differed in its exact job title and function across trusts. The employed individuals hence also varied in terms of their background, experience and interest in employee engagement.

- The largest bias for the survey involves the potential non-response of individuals within the sample with potentially no interest in behavioural energy efficiency in the first place.

- In addition, the sample size of the survey remains relatively small despite the satisfactory response rate due to the limited size of the original target population and the respondent routing. In cases such as these, the use of statistical analysis techniques is often limited and various studies have found that descriptive statistics provide a more suitable and effective means by which to analyse and interpret the data (Saunders et al. 2012). 


\section{Survey findings}

For the analysis of numerical survey data, a quantitative descriptive approach was used. Text inputs in response to opinion-type free questions were first coded and then analysed using an analytic inductive approach (Silvermann 2010). To test the association between different variables, some data was cross-tabulated and trends were analysed. The key findings are as following, the results on the basis of which they were inferred are summarized subsequently and discussed in detail below:

- Relevance: Taking into account survey non-response, it can be regarded as conservative estimate that $45 \%$ of NHS trusts in England were interested in exploring staff-centred energy conservation measures.

- Barriers: Apart from a lack of manpower to engage in staff-centred initiatives, the perception that building side initiatives were more promising was an important barrier to their uptake in hospitals.

- Implementation: Staff energy behaviours currently targeted in hospitals corresponded closely to those reported in the literature for other non-domestic building types.

Other findings included evidence for the scope of staff-centred energy conservation initiatives as well as the identification of further challenges to their implementation.

\section{Relevance of staff-centred energy conservation initiatives in hospitals}

According to the web-survey, $69 \%$ of the responding trusts (48 out of 70 ) had implemented staff-centred energy conservation measures since the beginning of the financial year $2012 / 2013$ with a further $27 \%(N=19)$ planning to do so during the current financial year. With only $4 \%(\mathrm{~N}=3)$ of respondents unconcerned, these results showed that behavioural energy efficiency was an area of interest for hospitals and their energy managers in reducing carbon emissions. Some caution will be appropriate with respect to the absolute numbers because these questions in particular were likely affected by non-response error. Taking the achieved survey response rate of $47 \%$ into account and assuming all non-respondents were unconcerned, it can be regarded as conservative estimate that $45 \%$ of NHS trusts were interested in exploring staff-centred conservation measures (Percentage of those interested * Percentage of those who responded to the survey: $96 \%$ * $47 \%$ ). Since at least some members of the target population will likely not have responded to the survey for other reasons such as lack of time, actual interest can be assumed to be somewhat higher.

\section{Barriers to implementing staff-centred energy conservation initiatives in hospitals}

Trusts who had not (yet) implemented any staff-centred energy conservation measures $(\mathrm{N}=22)$ most often stated the lack of manpower as reason for this $(25 \%)$, but also that building side initiatives were perceived as more promising (17\%) alongside with the unclear savings potential of behavioural initiatives (15\%), see Table 2. Several energy managers pointed out that they were 'not convinced that there are significant savings to be had from behaviour change campaigns' and that 'funding when available should be spent on improving technology and controls.' Apart from questioning the benefits of employee engagement, these quotes also pointed towards the importance of finance in the NHS in terms of winning funding and making cost savings. 
Table 2: $\quad$ Barriers to uptake (based on Q8)

\begin{tabular}{|l|c|}
\hline $\begin{array}{l}\text { Barriers to uptake } \\
\text { (Multiple answers possible) }\end{array}$ & $\begin{array}{c}\% \text { of } \\
\text { respondents }\end{array}$ \\
\hline $\begin{array}{l}\text { Insufficient manpower for decentralised and } \\
\text { continued action }\end{array}$ & $25.4 \%$ \\
\hline $\begin{array}{l}\text { Building side initiatives perceived as more } \\
\text { promising }\end{array}$ & $16.9 \%$ \\
\hline $\begin{array}{l}\text { Unclear saving potential of behavioural } \\
\text { initiatives }\end{array}$ & $15.3 \%$ \\
\hline $\begin{array}{l}\text { Lack of a clear policies for behavioural } \\
\text { initiatives }\end{array}$ & $13.6 \%$ \\
\hline $\begin{array}{l}\text { Uncertainty about how to best evaluate the } \\
\text { impact of behavioural initiatives }\end{array}$ & $11.9 \%$ \\
\hline $\begin{array}{l}\text { No backing for behavioural initiatives at } \\
\text { senior/board level }\end{array}$ & $11.9 \%$ \\
\hline $\begin{array}{l}\text { Structural uncertainty regarding who should } \\
\text { take ownership }\end{array}$ & $5.1 \%$ \\
\hline
\end{tabular}

Correspondingly, saving money was stated by energy managers with implementing experience $(\mathrm{N}=44)$ as the most important motivation for the implementation of behavioural initiatives from a trust perspective (average score of 4.4 on a 5 point scale where 5 is very important). Reducing carbon emissions came a close second (average importance of 4.1, not significantly different from the former at $t(44)=1.322, p=0.190$ ), followed with some distance by the desire to have a green image $(3.5, t(44)=3.427, p=0.001)$. Non-energy effects such as improving the patient experience and empowering hospital staff scored significantly lower, with average scores of 3.0 and 2.9 respectively.

\section{Implementation of staff-centred energy conservation initiatives in hospitals}

Of all staff-centred energy conservation initiatives, $81 \%(\mathrm{~N}=39)$ were carried out internally, while the rest $(\mathrm{N}=9)$ was carried out with some external support, but never solely externally. Information based initiatives to raise energy awareness among trust staff or patients proved most popular on the behavioural side and accounted for $13 \%$ of energy efficiency measures carried out by NHS trusts in 2012/2013 according to the 70 survey responses. This popularity only compared to upgrades of lighting or lighting controls with $18 \%$ and building or energy management system optimisations with 14\% (see Figure 2). On the behavioural side, the display of area specific consumption data or the provision of feedback on its basis were the second most commonly used approaches (7\% of all implemented measures), followed by energy champions, i.e. dedicated persons at ward or departmental level who engage colleagues and promote environmentally friendly actions (5\% of measures). Again, these numbers need to be understood with some caution, given that trusts not responding to this survey might favour building side over behavioural initiatives. 
Fig. 2 Overview of energy efficiency measures commissioned by NHS Trusts during 2012/2013 (based on Q1)

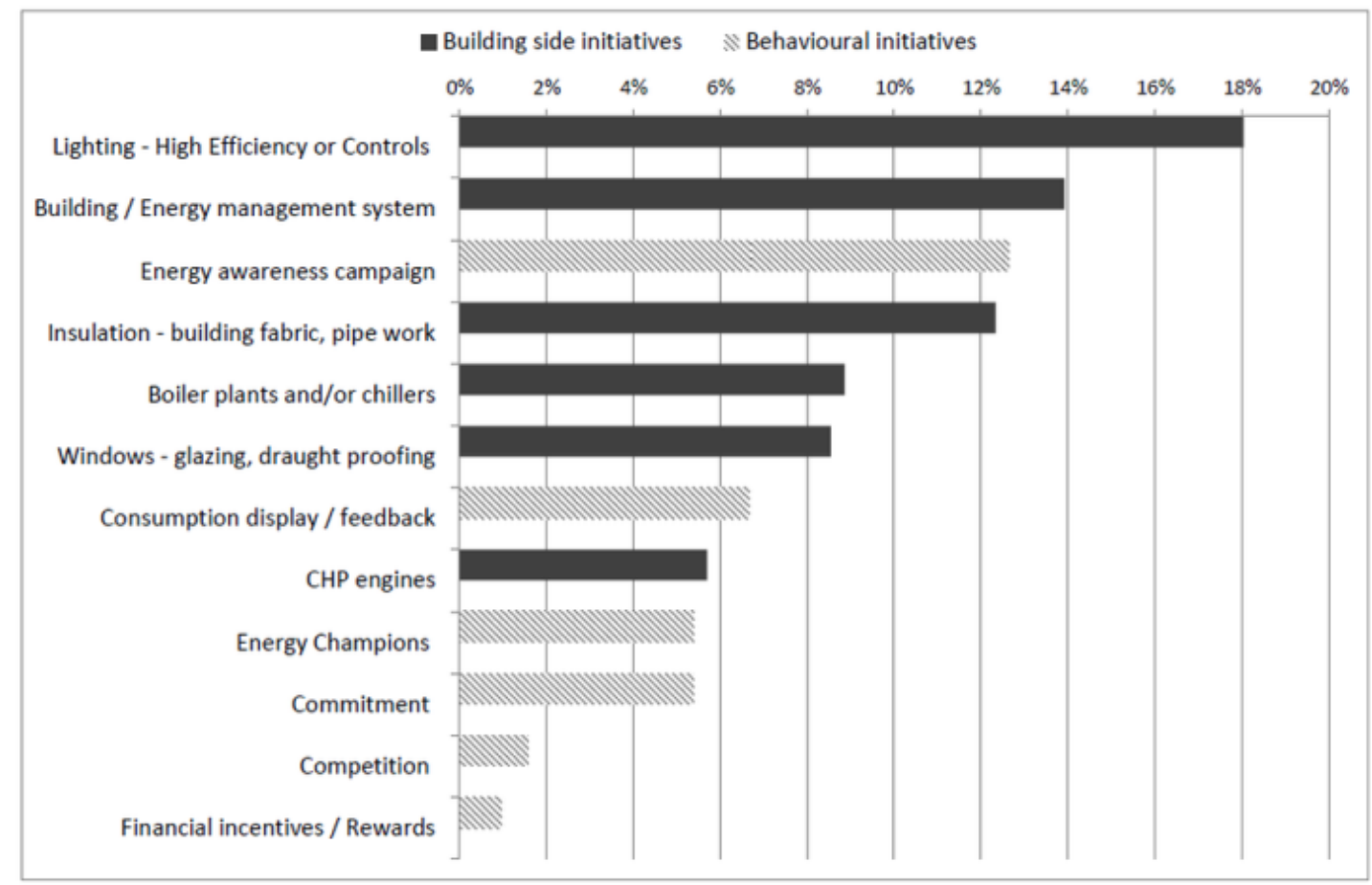

The energy behaviours targeted in hospitals corresponded closely to those reported in the literature for other non-domestic building types (see Figure 3). About $12 \%$ of initiatives each encouraged turning off unused equipment and switching off unnecessary lights, while $11 \%$ aimed at reducing the use of portable heaters. Therewith the three most sought after behaviours all referred to the use of electricity. The reduction of (some) heating set points featured in line with recommendations through the NHS Sustainable Development Unit (2010) as most popular heating fuel related behaviour in $8.4 \%$ of initiatives, followed by advice on energy efficient window use $(7.5 \%)$ and encouragement to report problems such as simultaneous heating and cooling $(7 \%)$.

It was also noticed that many initiatives seemed to target a large number of different energy behaviours. Among the survey respondents, the average number of behaviours targeted through some form of behavioural initiative (not necessarily one campaign only) was 7 , while some respondents indicated to address up to 14 energy behaviours. 
Fig. 3 Energy behaviours targeted by staff-centred energy conservation initiatives in hospitals (based on Q7)

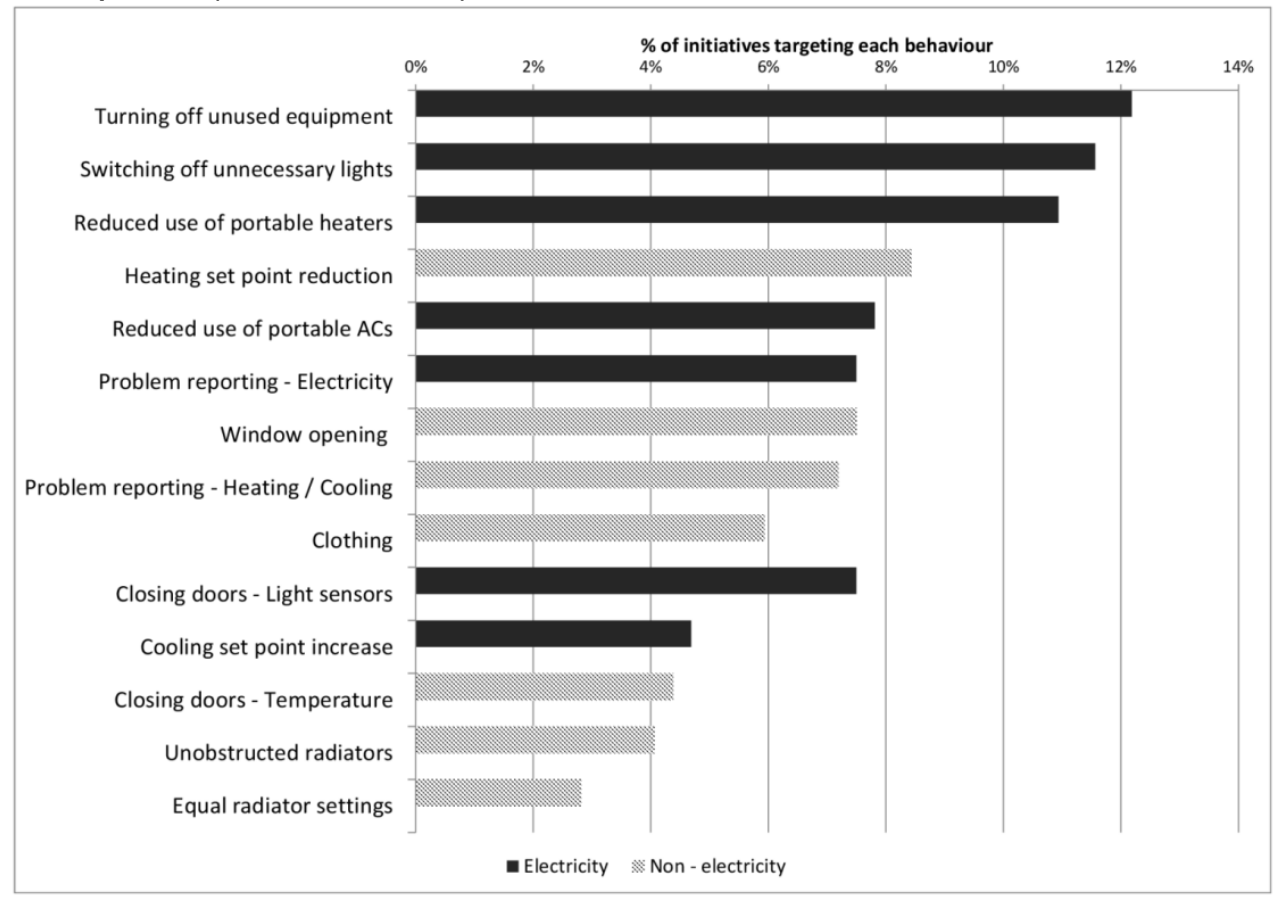

\section{Scope of staff-centred energy conservation initiatives in hospitals}

To compute cost savings and to gauge the success of behavioural measures in general, $68 \%$ of trusts used meter or billing data for electricity and $62 \%$ for the main heating fuel. In addition, $43 \%$ of trusts also applied more or less systemic observations or audits of the targeted behaviours. Self-reports of staff on their own energy behaviours, a typical approach in academic studies with a comparable purpose, were so far only used by $16 \%$ of trusts. $40 \%$ of trusts also collected some qualitative data during the implementation phase of the intervention. The survey did not ask about details of those approaches; they could hence range from randomly collected impressions of how engaged different areas/ teams were with initiatives to more systematic ward rounds with prepared questions or discussion topics.

During the survey, less than a fifth of the responding trusts ( $N=8$ out of 42 ) could provide a cost estimate for savings from behaviour change. Those that did, stated savings between 1 and $5 \%$ of total energy costs and therewith fell somehow short of aforementioned policy assumptions for example by the Carbon Trust who expects up to $10 \%$ cost savings through good housekeeping (Figure 4). With regard to energy, the NHS Sustainable Development Unit assumes a savings potential through energy awareness campaigns of $3 \%$ for electricity and heating, respectively. These numbers were echoed in the survey, although even fewer trusts ( $\mathrm{N}=4$ out of 37 ) could provide any estimate at all and accuracy might be questionable given the energy data available for evaluation purposes (see Table 3). This also became clear when looking at sizes of savings stated for the main heating fuel: Energy managers provided the same savings across all areas and for areas/teams that engaged well with the campaign, likely because any differentiation seemed impossible at the current rate of submetering. Similar issues will exist around the validity of the stated cost savings which in many trusts did not seem to relate to proven energy savings as indicated by the lack of relation between both in Figure 4.

The final publication is available in "Energy Efficiency" at Springer via http://dx.doi.org/10.1007/s12053-015-9346-2 
Table 3 Availability of energy data in General Acute Hospitals based on total gross internal area (irrespective of ownership) as of July 2013 (based on Q22 \& Q23)

\begin{tabular}{|l|l|l|l|}
\hline \multicolumn{2}{|c|}{} & Electricity & Main heating fuel \\
\hline \multirow{4}{*}{$\begin{array}{l}\text { Level at which } \\
\text { data is available } \\
\text { for use }\end{array}$} & At site level only & $41 \%$ & $50 \%$ \\
\cline { 2 - 4 } & At building level & $44 \%$ & $41 \%$ \\
\cline { 2 - 4 } & $\begin{array}{l}\text { Below building but } \\
\text { above floor level }\end{array}$ & $5 \%$ & \\
\cline { 2 - 4 } & At floor level & $1 \%$ & $5 \%$ \\
\cline { 2 - 4 } & $\begin{array}{l}\text { At } \\
\text { ward/departmental } \\
\text { level }\end{array}$ & & $0 \%$ \\
\hline \multirow{4}{*}{$\begin{array}{l}\text { Frequency with } \\
\text { which data is } \\
\text { available for use }\end{array}$} & Every month & $9 \%$ & \\
\cline { 2 - 4 } & Every day & $8 \%$ & $4 \%$ \\
\cline { 2 - 4 } & Every hour & $5 \%$ & $22 \%$ \\
\cline { 2 - 4 } & Every 30 min & $42 \%$ & $11 \%$ \\
\cline { 2 - 4 } & Every 5 min & $3 \%$ & $25 \%$ \\
\cline { 2 - 4 } & In real-time & $22 \%$ & $0 \%$ \\
\cline { 2 - 4 } & Other & $7 \%$ & $17 \%$ \\
\hline
\end{tabular}

Fig. 4 Comparative responses to Q14 (Cost savings) and Q16 to Q19 (Energy savings), bars indicating range of responses

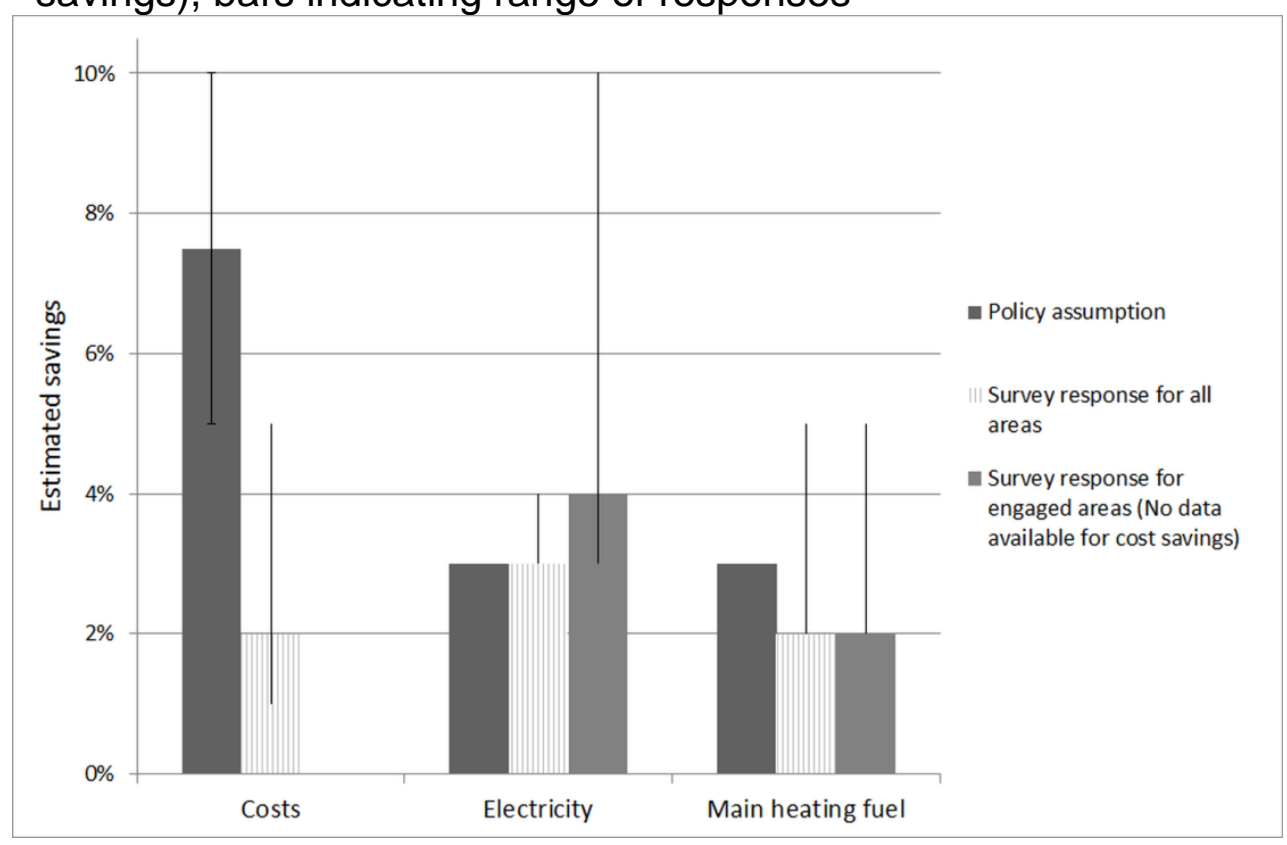

\section{Evaluative challenges for staff-centred energy conservation initiatives in hospitals}

The small number of trusts able to provide robust estimates for campaign savings made it clear that the evaluation of behavioural energy efficiency programmes in English hospitals was still a major challenge. Lack of time and/ or manpower within the implementing team to assess the wider impact of staff-centred conservation initiatives was stated by $19 \%$ of trusts as main hindrance. But insufficient sub-metering (16\%) as well as growth (increased service delivery, new buildings, and more equipment) within the analysed system boundaries (15\%) 
further complicated evaluative efforts. Even in hospitals with above-average sub-metering, it seems to be very difficult to measure and attribute changes in energy use to staff-centred conservation initiatives due to the complexity of building services, processes and appliance use in hospitals.

Evaluative challenges may be compared with respect to the delivery mode of initiatives. Results may, however, be understood as indicative only because the number of trusts, in particular those carrying out initiatives partly externally is very small $(\mathrm{N}=8)$ for statistical testing. A two-sample t-test assuming unequal variances was carried out comparing the mean frequencies of each evaluative challenges in trusts were initiatives were delivered internally $(\mathrm{N}=31)$ against those receiving some external support. The only statistically significant difference suggested that part-external initiative delivery may alleviate difficulties arising from a lack of knowledge on how to best evaluate behavioural initiatives, reducing the number of trusts quoting this challenge from $7.5 \%$ to $1.8 \%(t(39)=2.242, p=0.035)$. 


\section{Discussion}

Both survey findings and current recommendations for carbon mitigation within the NHS, for example by the NHS Sustainable Development Unit (2010), show some interest in staffcentred energy conservation initiatives. The interest of at least $45 \%$ of NHS energy managers as implementing arm of top-down energy efficiency strategies is encouraging and suggests this may be an area worthy of further investigation. At the same time, a number of open questions specific to the hospital context were brought up in the survey and will subsequently be discussed in the light of the evidence uncovered in the state-of-the art literature analysis.

\section{Cost-effectiveness as central concern for energy managers}

Survey findings suggest that the cost-effectiveness of interventions is a crucial criterion for energy managers in their decision-making on energy efficiency. Achieving cost savings and the availability of funds more generally seem to be the most important pressure for trust energy managers, as visible both from motivations given for implementing staff-centred initiatives and from the frequency these concepts are brought up in statements throughout the survey. This is in line with NHS communications generally, which following recent economic and political developments frequently stress the need to secure value for money and to live within available means whilst delivering their priorities (for example NHS England 2013).

At the same time, some uncertainty remains whether staff-centred conservation initiatives can indeed deliver cost-effective savings in the hospital context. In the survey, several energy managers express their doubts about this and building side interventions are perceived as more promising by $17 \%$ of survey respondents. A further $15 \%$ state the unclear savings potential as barrier for the implementation of staff-centred initiatives. Taking into account nonresponse to the survey, both of these numbers are likely to be even higher for the total population. One central challenge may hence be summarized as follows: Given the energy intensity of hospital buildings and processes, do clinical staff actually influence a substantial part of a hospital's energy use or are most parts of the energy requirement defined by necessary processes or centrally controlled?

\section{Potential of staff-centred energy conservation initiatives in hospitals}

As laid out in the literature review, no studies are known which explicitly investigate staff influence and energy behaviours in hospitals attempting to place them within the overall context of hospital energy use. For offices buildings in the US, Azar and Menassa (2014) have identified a $21 \%$ reduction potential from changes in building operation across the stock, using a combination of surveying and energy modelling. Most of these savings were projected to come from changes in thermostat set points, while reducing the after-hour use of equipment and lighting accounted for $4-5 \%$ and $1-2 \%$ of the savings potential, respectively. It may be noted that the potentials given in the study are to be understood as upper limits to what operational changes could achieve since they did not account for practicability limits. They are nevertheless useful indications as to whether the further exploration of such measures is worthwhile, both on the ground and in a policy context. 
Without further research, it is hard to estimate how saving potentials would compare for hospitals but they will likely remain at least within the same order of magnitude. Additional savings might arise from addressing hospital specific processes such as ventilation rates in unoccupied operating theatres, while survey findings suggest that staff energy behaviours currently targeted in hospitals correspond closely to those reported in the literature for other non-domestic building types. Further research identifying and quantifying the potential of energy behaviours specific to the hospital context would be beneficial to scope any additional potential here.

\section{Implementation challenges in the hospital context}

The survey suggests that NHS energy managers were further concerned with how staffcentred initiatives can successfully be implemented in the hospital context, i.e. how can busy and occasionally disinterested hospital staff be motivated to take a lasting interest in energy and resource use. Survey findings suggest that a variety of approaches described in the social and environmental psychology literature were currently being trialled across English hospitals such as providing information, feedback and occasionally rewards. The display of local energy consumption data and the provision of feedback on its basis were meanwhile limited by the lack of available meter data for both electricity but especially the main heating fuel.

On the whole, a number of successes were reported but it was also recognised that clinical staff are under pressure from many different areas and initiatives with energy falling short among their priorities. This challenge was previously also pointed out by Tudor (2008) with respect to waste management within the NHS. Likewise in agreement with Tudor's findings, some energy managers also stated that participation in campaigns seemed them to be strongly related to the environmental attitudes of individual staff and their behaviours at home. To overcome these challenges, literature variously suggests that senior management commitment to sustainability is crucial to implement pro-environmental behaviours as firm part of organisational cultures (see for example Cox et al. 2012). But while survey findings suggested that management commitment was not a major barrier for staff-centred conservation initiatives during conception, energy managers also pointed out that sustainability had 'gone down the agenda in 2012-13' following recent economic and political developments within the NHS and cost concerns were now the central criterion for strategic decisions.

The relatively small scale of achievable savings reported for hospitals in both literature and survey also highlights the importance of low implementation costs (both with respect to money and time) for initiatives to remain cost-effective. But in the survey, several energy managers express their doubts as to whether such initiatives can truly be delivered at low costs across hospital estates integrating many different buildings and functions. One energy manager describes this dilemma as following: 'This is a large Acute Hospital which covers a large area. The buildings are all of varying ages and conditions and therefore have different types of heating and air handling units which makes it difficult to put out a universal message.' It seems inevitable that such concerns regarding scalability will increase the cost of initiative design and possibly also implementation.

At the same time, the interplay between building performance and staff behaviour may not be 
overlooked, in particular with respect to thermal comfort (Baird 2010). UK hospitals are often known to be too hot or to experience other types of temperature control issues while clinical staff may legitimately expect to be provided with a well-functioning workplace for themselves and their patients and will otherwise take action to alleviate discomfort (Leaman 2000). Such situation is illustrated vividly by a quote from one of the survey respondents with respect to heating effectiveness: 'I believe the trust and possibly many trusts like ours need firstly to utilise their energy management systems to control more efficiently before undertaking these initiatives. As staff opinion seems to be if there heating is inefficient they purchase more subsidiary electric heating to substantiate this.' This suggests that staff-centred conservation initiatives need to be regarded within the overall context of building efficiency and may need to accompany or be accompanied by technical interventions if savings are to be achieved.

\section{Limitations of this study}

Although presenting interesting insights into an area which has so far received little academic attention, this study has a number of limitations. It was conceived as pilot study for a bigger project and is hence limited in its scope and reach. The main limitations are as following:

\section{Topical limitations}

The survey based study focussed on NHS energy managers as key stakeholders defining the carbon mitigation strategies in hospitals. In addition, both academic and grey literature were reviewed to identify broader principals of staff-centred conservation initiatives. In their job role, energy managers will have a good overview of the energy use in their trusts, both in response to reporting requirements and as basis for strategy decisions. Their focus, however, will be dominated by a top-down view which may to a certain extent be problematic in the context of staff-centred initiatives. Further research taking the perspective of clinical staff as targets of such initiatives would hence be useful to clarify pressures and motivations in their workaday and clarify non-energy effects. Such investigation would also be beneficial in identifying organisational or operational constraints on theoretically expected savings potentials. Finally, looking at buildings and processes through the lens of energy services (i.e. heating or cooling, ventilation, cleanliness that clinicians and patients alike require) might also help to bridge some of this gap.

\section{Methodological limitations}

Many of the identified issues with staff-centred conservation initiatives in hospitals are thought to be relevant in other health care systems and countries as well, but further research surveying for example NHS trusts in Wales or Scotland where organisational structures are similar and adopting the survey to other systems will be necessary to gather additional evidence. Increasing the target population would also allow for more statistical analysis, especially on questions which due to the branching of the survey have currently seen very few responses. Overall, routing the respondents specifically to questions relevant for them was found useful in keeping their attention, but may be more suitable for larger survey populations. In addition, carrying out a number of interviews may be useful to add depth to the investigation of challenges for the implementation and evaluation of staff-centred energy conservation initiatives in the hospital context. 


\section{Outlook}

Despite the presented limitations, this study has shed light on how knowledge of staffcentered energy conservation initiatives in hospitals may be advanced both at a theoretical and at a practical level. A number of survey respondents suggested that some guidance on which elements of staff engagement have worked well and which have not across the NHS estate could be insightful. To some extent, the NHS Sustainable Development Unit already attempts to meet this need through their website (NHS SDU 2014). It seems, however, that there is scope for additional communications presenting for example also robust methodologies to estimate effect sizes. Currently, evaluation remains difficult for many trusts primarily due to a lack of time/ manpower to access the wider impact of initiatives. Potentially increased collaboration for example with academic partners could be a way forward here.

Growth in service delivery or increased use of technology can also be problematic during initiative evaluation according to survey findings. Hospitals are a fast paced environment and especially medical equipment is constantly developing and changing to meet patient needs (NHS SDU 2013). The energy impacts of these factors are currently poorly understood. Due to the limited sub-metering available in UK hospitals (and indeed worldwide, see for example Benke et al. 2009 in Austria), the knowledge of hospital energy use from an end-use perspective remains extremely sparse. The survey has shown, however, that improvements to building or energy management systems were the second most frequently commissioned measure in English General Acute Hospitals in 2012/2013. This is promising and will help to better understand the role of staff-centred initiatives in hospital energy conservation in the future.

At a theoretical level, further research should address the following questions in order to clarify the role of staff-centred energy conservation initiatives within the context of all available carbon reduction strategies in hospitals:

- To what extent can medical staff influence hospital energy use in different healthcare processes and buildings?

- What is the theoretical energy saving potential from changes in specific energy behaviours in different hospital types and areas?

- What are the main individual, social, operational and organisational constraints on the theoretical savings potential?

Additionally, potential non-energy benefits of staff-centred conservation initiatives from both a trust and a staff perspective (such as increased workplace productivity or more fault-freely running buildings) should be analysed. Further research is needed here to clarify the interplay between motivations and pressures for hospital staff. 


\section{Conclusion}

Literature and survey study have shown that staff-centred conservation initiatives are an area of interest for hospitals and their energy managers aiming to reduce energy use and carbon emissions. Significant resources seem to currently get invested in development and implementation of energy behaviour change programmes in England (both through individual trusts and through the NHS as a whole) and a number of successful campaigns have been reported. Information based initiatives to raise energy awareness among trust staff or patients proved most popular on the behavioural side and accounted for $13 \%$ of all energy efficiency measures carried out by NHS trusts in 2012/2013 according to the 70 survey responses. The survey, however, also showed that while cost-effectiveness is a central decision making criterion for energy managers, it remains somehow unclear how much energy and therewith money can really be saved through energy awareness campaigns and others in hospitals.

The central doubts are twofold: firstly, with regards to the nature of healthcare and secondly, with regards to pressures on clinical staff as target population for such initiatives. Hospitals are very energy intensive environments due to their continuous operation, the need for high air change rates as well as the use of medical, sterilisation, catering and IT equipment. It hence remains unclear exactly how much the actions of clinical staff actually impact on total hospital energy use. It may be suspected that influence will vary across different buildings and healthcare processes, but further research is recommended to link energy behaviours in hospitals explicitly to the respective buildings, processes and their interfaces with the occupants. Given the difficulties energy manager report in putting out universal messages across hospital estates with buildings and systems of many different types and ages, such an approach will also be helpful in concentrating engagement efforts where they are meaningful.

In order to achieve lasting staff engagement, it also seems promising to directly involve interested clinical staff in campaigns as experts on healthcare processes, the use of respective facilities and local pressures. A wider network of actors may be conceivable to complement top-down efforts by the energy management team, potentially including academic experts helping program evaluations. At the same time, the conflicting demands on the time of both clinical and technical staff within a high-pressure environment such as the NHS need to be appreciated. The resources required for staff-centred campaigns can only be made available if a trust's senior management remains strongly committed to sustainability in times of rising pressures on NHS budgets. Staff efforts alone may also not be expected to replace sufficiently funded carbon mitigation strategies holistically addressing infrastructural as well as operational inefficiencies. These findings may reasonably be expected to apply beyond healthcare to other large scale public sector organisations likewise. 


\section{References}

Abrahamse, W., L. Steg, C. Vlek and T. Rothengatter (2005). A review of intervention studies aimed at household energy conservation. Journal of Environmental Psychology, 25(3), 273291.

Abrahamse, W., L. Steg (2013). Social influence approaches to encourage resource conservation: A meta-analysis. Global Environmental Change, 23(6): 1773-1785.

Aune, M., Berker, T., Bye, R. (2008). The missing link which was already there: Building operators and energy management in non-residential buildings. Facilities, 27(1), 44-55.

Azar, E., Menassa, C.C. (2014). A comprehensive framework to quantify energy savings potential from improved operations of commercial building stocks. Energy Policy, 67: 459472.

Baird, G. (2010). Sustainable buildings in practice: what the users think. London: Routledge.

Balaras, C. A., E. Dascalaki and A. Gaglia (2007). HVAC and indoor thermal conditions in hospital operating rooms. Energy and Buildings, 39(4), 454-470.

Banks, N., Z. Redgrove, M. Gunn, J. Mullen, J. Ryle, T. Fawcett, L. Ristic and S. Bird (2012). What are the factors influencing energy behaviours and decision-making in the non-domestic sector? London: Centre for Sustainable Energy (CSE), Environmental Change Institute (ECl).

Barts Health NHS Trust (2013). Changing Energy Behaviours in the NHS: Operation TLC. http://www.sduhealth.org.uk/news-events/news/214/Barts-Health-NHSTrust-saves-100000with-a-bit-of-TLC. Accessed 10 November 2013.

Benke, G., Leutgöb, K., Varga, M., Kolpek, M., Greisberger, H. (2009). Das energieeffiziente Krankenhaus. Realistische Ansatzpunkte und Maßnahmenidentifikation (in German). Wien: Bundesministerium für Verkehr, Innovation und Technologie. http://www.nachhaltigwirtschaften.at/results.html/id5726 Accessed 05 May 2013

Bicknell, C., Skumatz, L. (2004). Non-Energy Benefits (NEBs) in the Commercial Sector: Results from Hundreds of Buildings. ACEEE Summer Study on Energy Efficiency in Buildings. Pacific Grove, California.

Bordass, B., Leaman, A. and Ruyssevelt, P. (2001). Assessing building performance in use : conclusions and implications. Building Research \& Information, 29(2): 144-157.

Brayford, L. (2004). Carbon/energy management in healthcare. Best practice advice for the NHS in England on meeting the mandatory carbon/energy targets. Leeds: NHS Estates.

Building Research Energy Conservation Support Unit (BRECSU) (1992). Energy efficiency in hospitals by good housekeeping. Health Estate J, 48(8), 4-6.

Building Research Energy Conservation Support Unit (BRECSU) (1995). Energy savings in NHS hospitals. Good Practise Case Study, 202, 1 - 6.

The final publication is available in "Energy Efficiency" at Springer via http://dx.doi.org/10.1007/s12053-015-9346-2 
Carbon Trust (2008). Introducing NHS carbon management. Tech. rep., London, UK: Carbon Trust.

Carbon Trust (2010). Hospitals. Healthy budgets through energy efficiency. Guide CTV024, London: Carbon Trust.

Carrico, A. R., Riemer, M. (2011). Motivating energy conservation in the workplace: An evaluation of the use of group-level feedback and peer education. Journal of Environmental Psychology, 31 (1), 1-13.

Cox, A., Higgins, T., Gloster, R., Foley, B., Darnton, A. (2012). The Impact of Workplace Initiatives on Low Carbon Behaviours. Scottish Government Social Research. London: Crown.

Creswell, J.W., Plano Clark, V.L. (2011). Designing and conducting mixed method research. London: SAGE $2^{\text {nd }}$ ed.

Daamen, D., Staats, H., Wilke, H., Engelen, M. (2001). Improving Environmental Behavior in Companies: The Effectiveness of Tailored Versus Nontailored Interventions. Environment and Behavior, 33(2): 229-248.

Department of Energy and Climate Change (DECC) (2011). The Carbon Plan: Delivering our low carbon future. London: Crown.

Department of Health (DoH) (2006) EnCO2de- Making energy work in healthcare. Environment and Sustainability, London: The Stationery Office.

Department of Health (DoH) (2006a). Statistics on Energy Performance and Carbon and CO2 Emissions, NHS England, 1999/00 to 2004/05 (With Prediction to 2009/10). London: The Stationary Office.

Diez, K., Lennerts, K. (2010). Benchmarking im Krankenhaus - Schwerpunkte Energie und Instandhaltung (in German). In: Facility Management Messe und Kongress. Frankfurt (Main), Germany, pp. 377-385.

Emmerson, C., Frayne, C., Goodman, A. (2000). Pressures in UK Healthcare: Challenges for the NHS. The Institute for Fiscal Studies: www.ifs.org.uk/comms/nhsspending.pdf Accessed 10.05.2014.

Fan, W. and Z. Yan (2010). Factors affecting response rates of the web survey: A systematic review. Computers in Human Behavior, 26(2), 132-139.

Dillman, D. A., J. D. Smyth and L. M. Christian (2008). Internet, Mail, and Mixed-Mode Surveys: The Tailored Design Method, New York: John Wiley \& Sons.

Gray, S. M. (2011). Sustainable Healthcare, Health Knowledge:

http://www.healthknowledge.org.uk/interactive-learning/sustainable-healthcare. 
Jeffries, I. \& Rowlands-Rees, T. (2013). Energy Efficiency Trends Annual Report 2012/2013. Essential insight for consumers and suppliers of non-domestic energy-efficiency., EEVS Bloomberg New Energy Finance. http://about.bnef.com/white-papers/energy-efficiencytrends-annual-report-201213/ Accessed 10 November 2014.

Jensen, A.H. and Petersen, P.M. (2011). Energy efficiency in hospitals and laboratories. In: Energy efficiency first: the foundation of a low-carbon society: ECEEE 2011 Summer Study. Conference proceedings, 6-11 June 2011, Belambra Presquile de Giens, France.

Jones, C. S. (2001). Towards benchmarking in British acute hospitals. Health Services Management Research, 14(2), 125-138.

Junnila, S. (2007). The potential effect of end-users on energy conservation in office buildings. Facilities, 25 (7), 329-339.

Kattenstein, T., Unger, H., Wagner, H. (2002). Handlungskonzepte zur Optimierung des Energiebedarfs und der Energieversorgung der Ruhr-Universität Bochum. Abschlussbericht zum Vorhaben: IV A4-20600298 Optimierung der bestehenden wirtschaftlichen Energieversorgung der Ruhr-Universität Bochum (in German). Ruhr-Universität: Lehrstuhl für Energiesysteme und Energiewirtschaft.

Leaman, A. J. (2000). Usability in buildings: the Cinderella subject. Building Research \& Information, 28(4): 296-300.

Littleford, C. (2013). Energy use by individual office workers: Psychological and contextual influences on behaviour. PhD, Loughborough University.

Lo, S. H., G.-J. Y. Peters and G. Kok (2012). A Review of Determinants of and Interventions for Proenvironmental Behaviors in Organizations. Journal of Applied Social Psychology, 42(12), 2933-2967.

Lomas, K., R. Giridharan, C. Short and A. Fair (2012). Resilience of 'Nightingale' hospital wards in a changing climate. Building Services Engineering Research and Technology, 33(1): 81-103.

Matthies, E., Kastner, I., Klesse, A., Wagner, H.-J. (2011). High reduction potentials for energy user behavior in public buildings: how much can psychology-based interventions achieve? Journal of Environmental Studies and Sciences, 1 (3), 241-255.

McClelland, L., Cook, S. W. (1980). Energy-Conservation in University Buildings Encouraging and Evaluating Reductions in Occupants Electricity Use. Evaluation Review, 4 (1), 119-133.

McGuire, A. (1987). The measurement of hospital efficiency. Social Science \& Medicine, 24(9), 719-724.

Murtagh, N., M. Nati, W. R. Headley, B. Gatersleben, A. Gluhak, M. Alilmran, D. Uzzell (2013). Individual energy use and feedback in an office setting: A field trial. Energy Policy, 62(0): 717-728.

The final publication is available in "Energy Efficiency" at Springer via http://dx.doi.org/10.1007/s12053-015-9346-2 
NHS England (2013). Putting Patients First. the NHS England business plan for 2013/14 2015/16. http://www.england.nhs.uk/pp-1314-1516/4-1516/ Accessed 04 August 2014.

NHS Jobs (2014). Working in the NHS. https://www.jobs.nhs.uk/about_nhs.html Accessed 21 November 2014.

NHS Sustainable Development Unit (NHS SDU) (2010). Save Money by Saving Carbon. Decision Making in the NHS using Marginal Abatement Cost Curves. Cambridge, UK: NHS Sustainable Development Unit.

NHS Sustainable Development Unit (NHS SDU) (2013). Carbon Footprint update for NHS in England 2012. Cambridge, UK: NHS Sustainable Development Unit. http://www.sduhealth.org.uk/policy-strategy/reporting/nhs-carbon-footprint.aspx Accessed 04 August 2014.

NHS Sustainable Development Unit (NHS SDU) (2014). Case studies. [online] www.sduhealth.org.uk/resources/case-studies.aspx Accessed 05 March 2014

Nye, M., Hargreaves, T. (2009). Exploring the social dynamics of proenvironmental behavior change. Journal of Industrial Ecology, 14 (1), 137-149.

Oikonomou, V., Becchis, F., Steg, L., Russolillo, D. (2009). Energy saving and energy efficiency concepts for policy making. Energy Policy, 37 (11), 4787-4796.

Osbaldiston, R. and J. P. Schott (2011). Environmental Sustainability and Behavioral Science: Meta-Analysis of Proenvironmental Behavior Experiments. Environment and Behavior, 44(2), 257-299.

Pencheon, D., S. Cointet, J. Brown, J. Howley, I. Tennison, H. Greensmith and S. Wright (2009). Saving Carbon, Improving Health. NHS Carbon Reduction Strategy for England. Cambridge, UK: NHS Sustainable Development Unit.

Raw, G. J., M. S. Roys and A. J. Leaman (1993). Sick Building Syndrome, Productivity and Control. Property Journal, 17 - 19.

Saunders, M., Lewis, P., Thornhill, A. (2012). Research methods for business students. Harlow: Pearson $6^{\text {th }}$ ed.

Shadish, W. R., Cook, T., Campbell, D. (2001). Experimental and quasi-experimental designs for generalized causal inference. New York: Houghton Mifflin.

Schahn, J. (2007). Projekt Energiemanagment am Psycholgischen Institut der Universiät Heidelberg: Ein erfolgreicher Fehlschlag. [in German] Umweltpsychologie, 11 (2), 138-163.

Schonlau, M., R. D. Fricker and M. N. Elliott (2002). Conducting Research Surveys via E-mail and the Web. Santa Monica, CA: RAND Corporation. 
Short, C. A., K. J. Lomas, R. Giridharan and A. J. Fair (2012). Building resilience to overheating into 1960's UK hospital buildings within the constraint of the national carbon reduction target: Adaptive strategies. Building and Environment, 55, 73-95.

Siero, F. W., Bakker, A. B., Dekker, G. B., Van Den Burg, M. T. C. (1996). Changing organizational energy consumption behaviour through comparative feedback. Journal of Environmental Psychology, 16 (3), 235-246.

Silvermann, D. (2011). Interpreting qualitative data: methods for analysing talk, text and interaction. London, Sage.

Socolow, R. H. (1978). Saving energy in the home: Princeton's experiments at Twin Rivers. Cambridge, Mass.: Ballinger Pub. Co.

Sorrell, S., Dimitropoulos, J., Sommerville, M. (2009). Empirical estimates of the direct rebound effect: A review. Energy Policy, 37 (4), 1356-1371.

Staats, H., van Leeuwen, E., Wit, A. (2000). A longitudinal study of informational interventions to save energy in an office building. Journal of Applied Behavior Analysis, 33 (1), 101-104.

Stutchfield, D. (2013) Environmental Facilitators' Role. https://www.standrews.ac.uk/capod/environmentalprogramme/ Accessed 26.11.2014.

The King's Fund (2012). Public expectations and experience of services. http://www.kingsfund.org.uk/time-to-think-differently/trends/public-attitudes-andexpectations/public-expectations-and-experience-services\#references Accessed 04.09.2013

Tippköter, R. \& Schüwer, D. (2003). Leitfaden Energieeffizienz für Krankenhäuser (in German). NRW, Germany: Energie Agentur.

Tudor, T. L., S. W. Barr and A. W. Gilg (2008). A Novel Conceptual Framework for Examining Environmental Behavior in Large Organizations: A Case Study of the Cornwall National Health Service (NHS) in the United Kingdom. Environment and Behavior, 40(3), 426-450.

Ziebik, A., \& Hoinka, K. (2013). Energy Systems of Complex Buildings. London: Springer. 


\section{Appendix: Survey questions}

Q1: Since the beginning of the financial year 2012/2013, has your trust implemented any measures from one or more of the following categories? Please select all that apply or none.

\begin{tabular}{|l|l|}
\hline Building side initiatives & Behavioural initiative \\
\hline $\begin{array}{l}\text { Lighting-Upgrade and / or improved lighting } \\
\text { controls }\end{array}$ & $\begin{array}{l}\text { Information based initiatives to raise energy } \\
\text { awareness among trust staff or patients }\end{array}$ \\
\hline $\begin{array}{l}\text { Building or energy management system } \\
\text { optimisation }\end{array}$ & $\begin{array}{l}\text { Energy Champions on wards or in } \\
\text { departments i.e. dedicated persons to } \\
\text { engage colleagues and to encourage energy } \\
\text { efficient behaviours }\end{array}$ \\
\hline $\begin{array}{l}\text { Installation / Replacement of insulation to } \\
\text { roof, walls, pipe work and/or in boiler house }\end{array}$ & $\begin{array}{l}\text { Achieving commitment to energy efficient } \\
\text { behaviour from individuals e.g. through } \\
\text { pledges }\end{array}$ \\
\hline $\begin{array}{l}\text { Installation or optimisation of CHP (combined } \\
\text { heat and power) engines }\end{array}$ & $\begin{array}{l}\text { Competition between different areas (e.g. } \\
\text { wards) or teams for energy savings / actions }\end{array}$ \\
\hline Improved window glazing or draught proofing & $\begin{array}{l}\text { Displaying local energy consumption data } \\
\text { and / or providing feedback on its basis }\end{array}$ \\
\hline $\begin{array}{l}\text { Efficiency improvements to steam plants, hot } \\
\text { water boiler plants and / or chillers }\end{array}$ & $\begin{array}{l}\text { Providing financial incentives or other } \\
\text { rewards }\end{array}$ \\
\hline Other, Please describe & Other, Please describe \\
\hline
\end{tabular}

Q2: (if Information based initiative is selected in Q1) How can the information based initiative(s) undertaken in your trust best be described? Please select all that apply.

- General Information Campaigns to raise awareness for sustainability (e.g. general posters, events such as NHS Sustainability Day, etc.)

- Localised Information Campaigns to promote specific, desired energy behaviours (e.g. stickers on light switches or PC equipment )

- Advice on energy efficient behaviours as part of the introduction for new staff

- Putting energy efficient behaviours on the agenda at clinical or team meetings

- Dedicated training sessions on energy saving actions potentially including walk throughs

- Other, Please describe

Q3: (if Displaying local energy consumption data and / or providing feedback on its basis is selected in Q1) How was energy consumption data used to motivate energy efficient behaviours in trust staff and / or patients? Please select all that apply.

- Publically displaying energy consumption, potentially in real time

- Feedback on previously performed energy behaviours based on historical energy consumption

- Feedback on ward/department energy consumption in comparison with the consumption of comparable areas

- Other, Please describe 
Q4: (if Providing financial incentives or other rewards is selected in Q1) How can the incentives or rewards provided to encourage energy efficient behaviours best be described? Please select all that apply.

- Rewards to individuals or teams for energy efficient behaviours

- Re-allocation of cost savings from reduced energy use towards equipment and facilities at ward, departmental or building level

- Other, Please describe

Q5: How were the behavioural initiatives delivered?

- Internally (potentially using external materials,e.g. posters)

- Externally

- Both

Q6: From a trust perspective, how strongly were the behavioural initiative(s) motivated by each of the following aims? (5-point scale with 1 - Not at all and 5-Very strongly)

- Saving money / energy

- Reducing carbon emissions

- Empowering hospital staff

- Improving the patient experience

- Reducing problems with building services

- Having a green image

- Staff enthusiasm for energy efficiency

- Other, Please describe

Q7: Which types of energy behaviours were aspired to by the behavioural initiative(s)? Please select all that apply.

Lighting \& Equipment

- Switching off unnecessary lights

- Increased reporting of problems such as unresponsive occupant light sensors

- Closing doors of utility and storage rooms to avoid triggering light sensors by passers-by

- Turning off unused nonclinical equipment (PCs, PC screens, projectors, etc.)

- Other, Please describe

Heating, Cooling \& Ventilation

- Closing doors between areas with different temperatures

- Equal setting of radiator valves for all radiators in one room

- Keeping radiators and grates above radiators unobstructed

- Reduced use of portable heaters

- Reduction in (some) heating set points

- Reduced use of portable fans/air conditioners

- Increase in (some) cooling set points

- Wearing clothes appropriate for the season 
- Increased reporting of problems such as simultaneous heating and cooling

- Reduced window opening while heating or cooling systems are in operation

- Other, Please specify

Q8: Which of the following, if any, prevented the uptake of behavioural initiative(s) in your trust? Please select all that apply.

- Building side initiatives perceived as more promising

- Unclear saving potential of behavioural initiatives

- Uncertainty about how to best evaluate the impact of behavioural

- Little knowledge about behavioural initiatives in general

- Lack of a clear policies for behavioural initiatives

- No backing for behavioural initiatives at senior/board level

- Insufficient manpower for decentralised and continued action

- Other, Please specify

Q9: (if no behavioural initiative was selected in Q1) Is your trust planning to introduce any of the following behavioural measures during the financial year 2013/14? Please select all that apply.

- Information based initiatives to raise energy awareness among trust staff or patients

- Energy Champions on wards or in departments i.e. dedicated persons to engage colleagues and to encourage energy efficient behaviours

- Achieving commitment to energy efficient behaviour from individuals e.g. through pledges

- Competition between different areas (e.g. wards) or teams for energy savings / actions

- Displaying local energy consumption data and / or providing feedback on its basis

- Providing financial incentives or other rewards

- Other, Please describe

Q10 - Q12: As Q2 - Q4

Q13: Generally speaking, how successful do you rate the behavioural initiative(s) undertaken since the start of the finanical year 2012/2013? Please mark one answer below, where 1 means 'Not at all successful' and 5 means 'Very successful'. (Opportunity to comments as free text was provided)

Q14: Please give an estimate (in per cent) of how much behavioural initiatives reduced the total energy costs of your Trust during the financial year 2012/2013? (Numerical input or button to indicate 'No estimate available')

Q15: Which types of information were used to assess the behavioural initiative(s)? Please select all that apply.

- Electricity meters/bills

- Meter data/Bill information for the main heating fuel

- Systematically collected information (e.g. room temperatures) from a building 
management system

- Additional (temporary) monitoring data, e.g. using light, sound or window opening sensors

- Observation of targeted energy behaviours (Auditing)

- Staff reporting on their own energy behaviours in a survey

- Survey amongst patient/visitors on the perceived energy behaviours of staff

- Patients/Visitors reporting on their own energy behaviours in a survey

- Qualitative impression of how engaged different areas/teams were with the initiative

- Other, Please specify

Q16: In your trust's General Acute Hospital(s), how much electricity (in per cent) was saved in 2012/2013 averaged across all areas where the behavioural initiative(s) were deployed? (Numerical input, two no-answer options: 'No estimate available', 'I don't know')

Q17: In areas/teams that engaged well with the initiative(s), what was the biggest electricity saving? (Numerical input, two no-answer options: 'No estimate available', 'I don't know')

Q18: Based on the consumption of the main heating fuel, how much energy (in per cent) was saved in your trust's General Acute Hospital(s) in 2012/2013 across all areas where the behavioural initiative(s) were deployed? (Numerical input, two no-answer options: 'No estimate available', 'I don't know')

Q19: In areas/teams that engaged well with the initiative(s), what was the biggest saving (in per cent) of the main heating fuel? (Numerical input, two no-answer options: 'No estimate available', 'I don't know')

Q20: Which of the following, if any, impeded the evaluation of the behavioural initiative(s)? Please select all that apply.

Priority

- Estimation of the savings was not deemed necessary

- Little engagement of staff / patients with the initiative(s) resulted in effects too small to be measured

Resources

- Lack of time/manpower within the implementing team to assess the wider imp

- Lack of knowledge on how to best evaluate behavioural initiatives

Confounding effects

- Energy use also influenced through other (technical) measures carried out at the same time

- Growth (Increased service delivery, new buildings, more equipment, etc.) within the analysed system boundaries

- Areas changing use during the course of the program

Data availability

- No historical data available for the use as baseline

- Time intervals of the available data not corresponding to initiative period 
- Low participation in evaluation surveys

- Areas of initiative deployment not corresponding to metered areas

- Insufficient sub-metering

Other

Please specify:

Q21: For which NHS trust are you filling in this survey? This information will help us to look up additional information on estate sizes and building ages from ERIC. It will also simplify the administration of the survey. No data will be used in a manner which would allow identification of your individual responses.

Q22: Please characterise at which levels energy data is available in your trust's energy management system: For which percentage of the total gross internal area (GIA) of all buildings occupied by your trust (irrespective of ownership) can data be analysed at the following levels? Please give an estimate. (Options for both electricity and main heating fuel)

- At site level only

- At building level

- Below building but above floor level

- At floor level

- At ward/departmental level

- Other, Please specify

Q23: Please characterise the frequency profile of the energy data in your trust: For which percentage of the total gross internal area (GIA) of all buildings occupied by your trust (irrespective of ownership) can data be viewed on an energy management system with the following frequencies? Please give an estimate. (Options for both electricity and main heating fuel)

- Every month

- Every day

- Every hour

- Every 30 min

- Every 5 min

- In real-time

- Other, Please specify

Q24: What could this $\mathrm{PhD}$ or research in general provide you with to facilitate uptake and evaluation of behavioural energy efficiency measures in your trust? Please write in.

Q25: Thank you for taking the time to complete this survey. Your assistance in providing this information is very much appreciated. If there is anything else you would like to tell me about energy efficiency and behavioural action in your trust or this survey, please do so in the space provided below. 